\title{
Children's views of accident risks and prevention: a qualitative study
}

\author{
Judith Green, Laura Hart
}

\begin{abstract}
Objectives-To examine children's accounts of injury risks and opportunities for prevention.

Setting-Schools, youth clubs, and a holiday activity scheme in the south east of England.

Methods-Sixteen focus groups were held with 7-11 year old children. Transcripts of the discussions were analysed using qualitative methods.

Results-Children were knowledgeable about injury risks and how to reduce them. They also saw injury prevention as primarily their own responsibility. However, they were also sophisticated in their criticisms of generalised prevention advice, and evaluated safety messages in the light of local environmental and social knowledge. Personal experience was more often reported as a reason for risk reduction than formal prevention advice. Risks for injury were not isolated from other risks faced.

Conclusions-Effective educational interventions aimed at changing children's risk behaviour should build more on children's own competence and knowledge of their local environment, and stress the need to manage risks rather than avoid dangers. (Injury Prevention 1998;4:14-21)
\end{abstract}

Keywords: children's perceptions; focus groups; education

Recent reviews of the literature on the prevention of injuries to children have suggested that interagency approaches, which combine different strategies to reduce injury rates, are likely to be the most effective, but that educational interventions remain the most commonly used. ${ }^{1-3}$ Towner notes that "education" is properly defined widely, to include a range of activities other than merely informing the public about healthy choices. ${ }^{4}$ Recent interventions have been developed that take a more sophisticated approach than that of information delivery. One set of materials for teachers of children aged 10-11, for instance, aims to raise children's awareness of, and abilities to manage, risk so as to change risk taking behaviour. ${ }^{5}$ However sophisticated the approach to "edu- cation", though, effective interventions still need to resonate with the learner's own perceptions. It has been noted that little is known about how children conceptualise risk and the possibilities for injury prevention. ${ }^{4}$ Although there is literature on parent's views of risks to children, ${ }^{6}$ children's own views of risks and the possibilities for risk reduction have been relatively under-researched. Indeed it has been noted that children's accounts of health matters in general have been neglected by health researchers, who often see them as incompetent or irrational reporters. ${ }^{78}$ However, in areas where children are experienced, studies in other fields have demonstrated that their knowledge and abilities to account for that knowledge are sophisticated and amenable to research. ${ }^{910}$

Given the difficulties of evaluating local injury reduction programmes in terms of health outcomes (such as mortality or morbidity reduction), there is, perhaps, a need for more exploratory work on how educational messages are likely to be used by the children they are aimed at. This paper reports the views of children from the south east of England aged between 7 and 11, and draws out the implications for health promotion specialists working in the area of injury risk reduction.

\section{Methods}

This study used focus groups: facilitated group discussions with children. Focus groups have been used with considerable success to examine not only the content of everyday knowledge about health related matters, but also to provide insight into how that knowledge is arrived at within peer groups. ${ }^{11}$ As peer group norms are likely to be an important factor in children's risk taking behaviour, group interviews offered a way of discovering how children talk to each other about risk. Although it is not claimed that children's talk in the presence of an adult researcher is identical to their talk in natural social settings, the group discussion were less formal than a structured interview. It has also been suggested that the group is a less inhibiting research format than the one-to-one interview, which is an important consideration for research with children. ${ }^{12}$

In order to draw on as wide a range of children's experiences as possible, we selected 
Table 1 Focus groups

\begin{tabular}{|c|c|c|c|c|}
\hline Group & Place & No of children & Rural/urban & $\begin{array}{l}\text { Gender }{ }^{\star} \text { and age } \\
\text { range (years) }\end{array}$ \\
\hline 1 & Saturday club & 8 & Rural & M, 7-8 \\
\hline 2 & School 1 & 8 & Rural & $M, 7-8$ \\
\hline 3 & School 1 & 7 & Rural & $M, 7-8$ \\
\hline 4 & Play scheme & 5 & Urban & $M, 7-11$ \\
\hline 5 & Play scheme & 6 & Urban & $\mathrm{B}, 7-11$ \\
\hline 6 & School 2 & 6 & Urban & $M, 7-8$ \\
\hline 7 & School 2 & 13 & Urban & $\mathrm{M}, 7-8$ \\
\hline 8 & School 2 & 3 & Urban & $\mathrm{M}, 10$ \\
\hline 9 & School 2 & 4 & Urban & $\mathrm{G}, 10-11$ \\
\hline 10 & Play scheme & 5 & Urban & $\mathrm{G}, 7-10$ \\
\hline 11 & School 2 & 3 & Urban & B, $7-8$ \\
\hline 12 & School 3 & 7 & Urban & $\mathrm{M}, 10-11$ \\
\hline 13 & School 3 & 8 & Urban & M, 7-9 \\
\hline 14 & School 4 & 5 & Rural & M, 9 \\
\hline 15 & School 4 & 5 & Rural & M, 9 \\
\hline 16 & Boy scout group & 6 & Urban & B, $7-11$ \\
\hline
\end{tabular}

${ }^{\star} \mathrm{G}=$ girls, $\mathrm{B}=$ boys, $M=$ mixed.

Table 2 Focus group prompts

Can anyone tell me what they think an accident is?

Has anyone had an accident recently? Seen one?

What happened? How did it happen? Could anything have stopped it?

Was it anyone's fault?

How do accidents happen?

How do you know if something has happened by accident?

How can we stop accidents happening?

What kind of advice do adults give you about avoiding accidents?

Is it good advice? Do you always follow it?

Do some children have more accidents than others?

16 groups from locations in several urban and rural areas and included schools with varied enrolment in terms of social class and ethnicity. However, the sample of locations cannot be taken as representative of Britain generally. Neither can the participants in groups (who were volunteers or, occasionally, "chosen" by teachers) be taken as representative of the locations they were sampled from. The groups included in the study are listed in table 1. Quotes in this paper are tagged with the group number.

Group discussions were held in the schools, play scheme, and clubs from which the participants were recruited. Play schemes are nonresidential holiday activity schemes organised by local authorities. All schools in the study were state, that is non-fee paying, schools. Five groups were single sex, with the others mixed. Some groups were "friendship groups": groups of children who reported playing together. Others consisted of children who knew each other less well. The number of children in the groups ranged from three to 13. Group facilitators used a series of prompts to stimulate discussion (see table 2), which was audiotaped with the children's permission.

Permission was sought from parents to include their children in the study with a letter explaining the project, and children were asked to volunteer for participation after the facilitator explained the purpose of the study. They were assured that names and other details would be changed to ensure that their comments would be confidential in any published reports. Study reports were circulated to the head teachers, youth club leaders, and play scheme workers, and parents were invited to contact the researchers if they wanted details of the main findings. Group facilitators were the two authors (both sociologists experienced in qualitative interviewing), and a research assist- ant who was a youth worker trained in interview skills.

Transcripts of the discussions were analysed using qualitative methods, using some of the techniques of grounded theory. ${ }^{13}$ Qualitative analysis is particularly useful where the aim is exploratory, and focuses on how participants understand the world, rather than testing formal hypotheses. Analysis involved examining the transcripts in detail to identify the range of ways in which children talked about accidents and how they accounted for injuries they had experienced. Recurrent themes in the discussions (such as responsibility, blame, cause) were then systematically coded, extracted with the aid of a word processor and collated. Dimensions of each theme were identified. For instance, the theme "blame for injury" had dimensions of blaming self, blaming known other, blaming unknown other, blaming no-one. These dimensions were compared across different contexts, such as gender of speaker, whether discussion was held in a school or relatively less formal setting of youth club, whether they occurred in response to direct questions or to comments from other participants. Some basic quantitative analysis was carried out to validate analysis, such as counting the number of stories of different types told in different contexts. Theoretical aspects of the methodology are described in detail elsewhere. ${ }^{14}$

\section{Results}

WHAT IS AN ACCIDENT?

We began the discussion groups by asking participants what they thought "an accident" was. Although some mentioned happy events, such as meeting a friend when out, and others talked about minor material damage, such as broken toys, the majority of responses described bodily injuries. The participants' initial definitions stressed two aspects that apparently characterised "accidents". The first was that they are unpredictable misfortunes, as Matthew suggests:

Facilitator: How d'you know if something's happened by accident?

Matthew: 'Cos you don't know it's gonna happen... (2)

As well as being unpredictable, an accident was also typically described as a motiveless injury, which no one intended to happen, as Ade notes:

Ade: I think an accident is an injury not done on purpose. (4)

For these children, any injuries that were deliberately caused were clearly not "accidents":

fason: If she pulls your hair, you can't do that by accident, you can only do that by purpose. (1)

However, as children began to tell stories about "real" accidents which they had experienced or witnessed, it became clear that such definitions as those above served only as idealistic definitions. Like public health experts, children perceived real accidents as caused by an enormous range of risk factors, which could - at least potentially — be managed and 
reduced. Few were unproblematically motiveless, or unpredictable, or unpreventable.

Real "accidents", as they were related in stories about their experiences, were, in fact, the subject of intense debate about motive, responsibility, and predictability. Indeed, the injuries suffered or seen by the children themselves were only provisionally labelled as "accidents". In discussion, the very factors that define ideal "accidents" were often explicitly questioned. In the stories about accident experiences told by these children, the word "accident" was used merely to flag a misfortune as the kind of event where some analysis of predictability, cause, and blame would be appropriate. For example, in the discussion below, boys from the play scheme debate whether an incident (witnessed by Curtis) was an accident. He reported having seen a woman driving her car into the back of a lorry which had stopped suddenly on the motorway. Several of the boys shouted that this wasn't an accident:

Facilitator: Why don't you think that was an accident?

Darren: No, no, if the lorry had stopped the woman must have known there could have been something wrong... so she could have stopped instead of carrying on driving... it was the woman's fault...

Ferome: She wanted to kill herself, I think.

Shane: She should have stopped instead of carrying on driving.

ferome: But then again I think it's the man's fault because nobody I know would stop in the middle of the motorway when he knows cars are behind him...

Darren: She probably did [try to kill herself] because she didn't have a seat belt on or anything...

Curtis: ...but she did have her seat belt on... (5)

The nature of an event, such as an injury, is not enough to define it as an accident. In this example the children engaged in detailed inquiry about both motivation and responsibility for the outcome to decide whether it was an accident or not. Sometimes even where an event was specifically introduced as an example of an accident, it's "accidental" status was rejected after discussion.

RESPONSIBILITY

If the children we talked to were in agreement that accidents were neither (at least in their experience) unpredictable nor necessarily unmotivated bolts from the blue, they were also in agreement that their own safety was primarily their own responsibility. They described themselves as responsible in two senses. First, they saw it as their own job, rather than that of adults who cared for them, to keep themselves safe through managing risks. Second, when such management broke down and injuries occurred, they accepted the blame ("my fault") for what they suffered. Whether they were discussing injuries they had experienced, those that had happened to their friends, or incidents they had witnessed or heard about, the participants in all our groups were unwilling to blame either other agents, or "bad luck". When asked "What causes accidents to happen?", partici- pants in all groups focused on their own behaviour:

Fatima: 'Cos we don't look where we are going to go. That's why we have accidents. (6)

Rachel: Not being careful.

Facilitator: Not being careful-anything else? Angela: People not thinking.

Stacey: Not looking where you are going.

Kelly: Leaving stuff around. (3)

Even after listing a whole series of events, such as the school bus crashing and a fire on a train, as examples of accidents, this group of girls still focus on their own behaviour when asked what causes accidents:

Facilitator:... so what do you think causes accidents to happen?

Hayley: Not being careful...

Nicole: Being silly...

Estelle: Playing in the wrong places...

Nicole: Messing around...

Estelle: Doing the wrong things... (10)

Participants in many groups did suggest specific "engineering" type interventions that could reduce injuries in their environments. These included lower traffic speeds, more pedestrian road bridges, "softer car bumpers" or signs warning of dangers, such as cliffs. However, it was notable that these were only mentioned when talking about accidents in general. When describing their own experiences of accidents, children focused on their own behaviour, rather than that of outside agents such as car drivers, authorities responsible for setting traffic speeds or parents. For instance, Janet, Emma and Danielle, from three different groups, all accept responsibility for these minor bicycle accidents:

fanet: ... we'd been on a bike and we were cycling around and it was my fault, and 'cos I scraped the kerb with the wheel by accident 'cos I was going a bit too fast and 'cos they had, um, sawed off the screw where you put the bell and the screw went right into my leg. (2)

Emma: My mummy and my daddy bought me a mountain bike and when I went for my first ride, I put my wrong brake on and I went over the bike. (1)

Danielle: It was my fault [I fell off] 'cos I was going too fast. (6)

One girl went further in her suggestion that all such accidents would be the fault of the rider: "Well, if you're riding a bike and if you had an accident, well it must be your fault, 'cos you're riding it". (8)

Even in situations where another agent, such as a car driver, could perhaps be held legally responsible for the occurrence of an injury, children often still reported their own behaviour as likely cause. In this discussion, for instance, Darren had told a story about a friend who was knocked over by a car on a zebra crossing after visiting the shop:

Darren: ... yeah, and the car hit him, and knocked him all the way round to [local football ground].

Facilitator: Whose fault was that, do you think?

Darren: His, 'cos he was deep into his bag of sweets! (5) 
Responsibility is not, of course, identical to culpability, but even in stories in which children claimed that a misfortune was "noone's fault" they were still willing to apportion some general responsibility, or contributory negligence. Here, for instance, Florence's friend Emma commented on an injury Florence suffered when she attempted to flick a playground swing over the top of its frame, and cut her head badly:

Florence:... I just standed and then the swing came bashing on my head.

Emma: Yeah, it was just an accident. She shouldn't have flicked it, but it wasn't her entire fault. (9)

Stories about injuries were couched in moral terms, with participants willing to accept blame for their own injuries and responsibility for keeping themselves safe. For girls, particularly, this sometimes went further, in that they also accepted responsibility for keeping younger children safe:

Vicky: I've done an accident to my brother before... I slammed [the door] closed and it slammed by brother's finger in the door ... I should have had more responsibility for him, 'cos I'm the oldest. (2)

\section{PREVENTION ADVICE}

Following on from their acceptance of responsibility for their own safety, children were adept at preventative thinking. Indeed, if individuals suggested that some injuries "just happen", peers quickly challenged this notion. Here, for instance, Florence offers the view that some accidents are inevitable, but her friends disagree, providing an example from their earlier discussion to illustrate the possibility (at least in theory) of prevention:

Florence: Accidents are accidents-they'll happen just like an accident.

Emma: But you can prevent them.

Tunde: Yeah, like the knife one, if the handle hadn't been sticking over... (9)

Similarly, they were reluctant to see injuries as the result of merely "bad luck". In all 16 groups, only one participant mentioned "bad luck" specifically as a cause of injury, and his opinions are marginalised by his friends:

Leroy: It's a coincidence, like. Some people get accidents and some don't.

Matthew: Don't use them big words, Leroy!

Leroy: It [friend's accident] was unlucky. It shouldn't have happened.

All:[Loud noises of protest]. (16)

Children offered many examples of injury prevention advice they had been given. Like the general ideal definitions of accidents offered, these examples of accident prevention advice were initially in general and abstract terms, often in chorus, with chants of "look left and right when you cross the road" or "don't talk to strangers" in reply to the facilitators' question "How can we help prevent accidents?". More specific advice from parents was reported as consisting mainly of prohibitions, or "warnings and stuff" as Adam (group 14) put it. Jason's and Ben's lists illustrate the flavour of such "warnings":
Fason: And my dad, and he tells me not to pick up any buggy things or don't touch dogs without asking the owner and don't take anything. If a stranger says, " $d$ 'you want my sweets?" say "NO"-if it's one of your friends you can say yes. (1)

Ben: My mum always says when I go to the shop, she says "Mind the road, look left and right, listen in case some cars are coming from the corner", or "don't be too long in case strangers come and take you away". (7)

Prevention advice remembered from school was, it seemed, also largely about prohibitions. This was effective in terms of the children's recall, and individuals in most groups reported detailed advice they had been given about crossing roads safely, safety on railways, and about "strangers".

When asked about the value of this advice, many children recognised that it was sensible and that they agreed with the aims. However, like the "ideal accident", this idealised advice was seen to be rather less useful in practice as a way of reducing the number of injuries. Again, when it came to discussing their own experiences, rather than accidents in abstract or hypothetical cases, children reported injury prevention as involving a rather more sophisticated balancing of risks than such generalised advice provided. In the discussions, several barriers to using this advice could be identified. These were: the undesirability of a risk free environment; advice that was too general to be useful in practice; the complexity of risk factors to consider; and the fact that risk behaviour happens not just as a result of individual choice, but as part of group activity.

\section{UNDESIRABILITY OF A RISK FREE ENVIRONMENT}

First, much advice was perceived as removing all risk from children's games, and some children (particularly the boys) reported that a completely risk free environment would be "no fun". As Mehmet commented, "without accidents, life wouldn't be fun". There are, he thought, opportunities for risk taking in childhood that do not last forever, and should be acted on while young:

Mehmet: Well I reckon little children should have fun while they can, 'cos when they grow up, they're not gonna do that kind of stuff, so they should do it now! (8)

Other children admitted to taking risks that they had been advised to avoid in order to counteract boredom:

Carole: There's this fence thing I normally climb over and it's got spikes. Yeah, it's a bit dangerous to climb. My mum tells me not to, but I still do it.

Facilitator: So why d'you think we don't always take that kind of advice?

Carole: 'Cos it's boring! (13)

Given the need to balance "boredom" and "danger", repeated advice to just "take more care" was seen as potentially counterproductive. First, it could encourage children to take risks, as Kenny suggests in the extract below, and second, it insults their competence, as Mehmet notes: 
Mehmet: In [TV programme] there's a karate thing with all knives and all that, and you kick each other and all that, well, when it finished, or like the break or something, they go "they're specially trained martial arts".

Kenny: Like in Power Rangers...

Mehmet: ...experts. So don't copy them. Like obviously, we know that! On that programme, every day he says that. Every day!

Kenny: That's because like there's little children...

Femi: But little children do it anyway!

Kenny: That makes them do it even more! (8)

ADVICE IS TOO GENERAL

The second limitation was the generalised nature of advice, which could not possibly take into account the specific risks of their environments or their own experience of those environments. Detailed local knowledge could be a better guide to taking risks than parental blanket prohibitions, as Carl explains in his account of why he ignored this advice from his parents:

Carl: [Parents say] don't ride on the road...

Facilitator: And do you ride on the road?

Carl: Yeah!

Facilitator: And why do you do that?

Carl: 'Cos there's not many cars that come up and down our road. (2)

Even when adults' advice was accepted as being sensible, children's accounts suggested that personal experience is still the crucial factor influencing their decisions. Here Darren explains why he now uses the school crossing patrol:

Darren: My cousin got knocked down and broke his ankle ... because he was just being silly. Where he goes to school in Derwent Road he has a lolly pop lady, but he doesn't want to [cross there], he wants to act like the rest and cross the road. And this time all the rest got across the road and he was in the middle of the road, waiting for a car and the car went past him that way and he didn't see another car and it swerved and hit him. (5)

As well as stories about injuries suffered by known others that legitimised their own risk avoidance strategies, children also discussed their own experiences of "near misses" as an influence:

Kenny: When you're on the road, like, even though people say look right and left, maybe you should always do that, because it's happened to me once. I was walking, and there were no cars, I was walking and a car just went "shoom" just in front of me and I went "uuhh" so that's why now I start looking. (8)

Thomas: Last Saturday I went to the park-I was on this pole and when I was half way down I lost my grip on here, lost my grip with my feet, and I was only holded on with one hand and slid down... I thought that, um, I'm not going on there again. (2)

COMPLEXITY OF RISK FACTORS TO CONSIDER These children, it seems, had accepted the logic of the Department of Health's view that "most accidents are preventable" 15 and that, in theory at least, all such misfortunes could be prevented. However, they were also quick to point to both the logical contradictions and the complexity of risk factors to consider, which between them limited the applicability of such theoretical prevention. Although, in theory, taking more care would prevent injuries, in practice "more care" was not always possible:

Simon: When I was drying up ... the plate slipped out of my hand, and I got grounded for a week. I didn't think that was fair!

Sam: Well, you should have been holding it with two hands!

Simon: Well, if I'd been holding it with two hands, I wouldn't have been able to dry up, so Sam's a bit wrong! (16)

In addition to the logical impossibility of some risk avoidance, children also pointed to the need to balance different risks. Minimising one risk could, for instance, increase another, as Tim pointed out:

Tim: ...we get told not to ride on the road [by parents] but this policeman walked along one time and then said "why are you riding on the pavement?" ... he said "'cos its not fair for the other people who are walking, and go and ride on the roads". That's why I ride on the road now. (2)

Carl, Tim, and Sarah discussed, in a hypothetical situation, the difficulties of managing risks on the roads when there are so many factors to consider:

Carl: But they [traffic accidents] would still happen, 'cos you don't, someone could be on the wrong side of the road 'cos they're trying to overtake and you don't know they're there...

Tim: ... yeah-there's another car coming and it just smashes into them-they don't know their brakes are working, and, they brake too late and, and crash into the other car...

Sarah: They could be overtaking round a corner. (2)

The multiplicity of risks that must be taken into account means that specific advice about a single risk factor may be less useful than it first appears.

INJURY IN THE CONTEXT OF GROUP ACTIVITY "Taking risks" relieves boredom and provides a way of testing developing physical skills and competence. For groups of friends, injuries and "near misses" also provide a store of "stories" that form part of the shared culture of the peer group. Many of the stories we were told in discussions were told by several children at once: they were clearly part of the remembered history of the group. In this context, such stories are a vehicle for producing and rehearsing group norms. Introducing a story as an "accident story" produces a space for debate around such issues as responsibility, culpability, and predictability. In this sense "accidents" are to avoided at some levels (most children agreed that it was wise to prevent them) but stories about them served a social function at others. Here, for instance, two boys excitedly compare notes on one game they play in which injury appears to be a major risk:

Mehmet: Boys normally play wild games, like ... dangerous, like when you keep on running and like... 
Kenny: ...yeah, like when we play that wrestling game...

Mehmet: ...yeah, like you push and...

Kenny: ...you can scrape your hand or even break your hand!

Mehmet: Whenever I play that game I always injure myself. Like I nearly broke my finger, I couldn't move it, last time...

Kenny: ...when that boy jumped. (8)

Such group norms do not always act as a barrier against risk reduction. Here, for instance, two friends agree on why they wouldn't take a "dare", even if someone threatened to break a friendship as a consequence:

Facilitator: Do you ever dare people to do things?

Emma: Yeah, but not dangerous things like that.

Tunde: Not dangerous stuff.

Facilitator: If somebody did dare you to do something dangerous, would you do it?

Tunde: No, I wouldn't.

Emma: No, never.

Tunde: No.

Emma: If they dared me to do something dangerous, and I was worried about losing my friends, well they're not my friends really. (9)

Their agreement about this issue, and the way in which they echo each other's comments, is clearly a bond between them and a way of reiterating a friendship.

INJURY IN THE CONTEXT OF DAY-TO-DAY LIFE The barriers identified to using some injury prevention advice also suggest that "accidents" or even "injuries" were not always easily isolated from other aspects of day-to-day life. Indeed, in response to questions about accidents experienced or seen, many children offered stories that would not be classified as "accidental injuries" in any formal data sets. Here, for instance, Tunde replies with an account of abuse she suffered from a babysitter when younger:

Tunde: ...I don't know what made her do it 'cos I was still a baby, about 1 or 2 or 3 , and she just, she just, I'm not sure how she done it actually, but she, it was quite her fault because she done something and one time I had to go to hospital and have stitches because she threw a high heeled shoe at my head. And my mum didn't know about it, and some people wanted to take ... me away from my mum. (9)

Similarly, the facilitator's invitation to talk about accidents was met with this response from a boy in one of the urban groups:

fosh: I've witnessed a murder at the back of my block ... there were these two men, right ... and one shot the man right in the back of the head. (12)

and this from another group:

Curtis: .. and some people are racist... Black people don't like white people, and white people don't like black people... and they do things to them that hurts them.

Facilitator: But is that an accident, Curtis, do you think?

Curtis: No.

ferome: It's sort of an accident though. (5)
Although the children, on reflection, may not see these misfortunes as "accidents" specifically, the fact that they are raised in the context of a discussion about accidents provides some clues to how prevention advice is integrated into their everyday lives. Such advice is clearly not perceived in isolation. It is first contextualised by formal education about a variety of other risks that they might face. Many groups, for instance, mentioned information they had been given in schools about "strangers" and listed these as a "danger" to be avoided. Others talked about the dangers of smoking or drug use. Although the participants from the urban groups, perhaps predictably, were more likely to talk about issues such as drug use, racism, or violent crime, children in all groups discussed accidents against such a backdrop of wider concerns, even in a focused discussion.

Formal advice about injury prevention was part of a network of messages these children receive about reducing risks. Other messages are less formal: from personal experience, or that of siblings and friends. Examples of such experiences from our transcripts include stories about a cousin who got run over and a friend who tripped on a railway door. It may be that referring to these examples was a more legitimate way for many of these children to defend their risk averse behaviours, such as crossing with the school crossing patrol. "Personal" experience could be extended to known characters in popular television programmes as well, such as 999, Casualty or Eastenders, as Carmen suggests:

Carmen: Like there was that girl, Cathy, in Eastenders, her friends dared her to pull a twig out of the fire, and she said "no, no", then she did and she got burnt. (12)

For many groups of children, examples taken from personal experience or popular television drama are likely to carry more cultural authority than advice from visiting policemen or railway safety advisors. Tunde, one of a group of 10 year old girls, for instance, legitimates her advice to the group to be careful of hot water with reference to a "true life film" she has seen:

Tunde: ...I'm not sure if it was a pot or a kettle or something ... and the little girl she climbed over something like a chair and she stood on the table and ... it poured all over her, and she's got scars on her face, like her skin peeled off. (9)

Messages about injury prevention come from television, parents, friends and personal experience, as well as from formal educational interventions. In Tunde's example above, the message legitimises injury prevention, but other messages, such as Mehmet's claim that "boys play wild games" (above), perhaps act as barriers to injury prevention. Children have to negotiate a complex set of sometimes contradictory rules for behaving in their environments, and injury prevention may not always be their first priority. Other risks (such as loss of status within a group which admires risk taking behaviour, or boredom) have to be balanced against injury reduction. 


\section{Discussion}

Although this small scale, exploratory study was not designed to evaluate any particular educational intervention, the findings about children's perceptions suggest some useful factors for consideration in the design of educational materials for these age groups. First, it may be encouraging for health promoters to note that the participants in these focus groups accepted the logic of accident prevention in theory, agreed with the aims of safety education in general, and accepted personal responsibility for keeping themselves safe. Indeed, they even challenged their peers who claimed that accidents "just happen". However, they were also critical of the limitations of some prevention advice in practice. From the stories they told about injuries and accident risks, it was clear that this knowledge about limitations was embedded in everyday knowledge about the wider social environment, in which the risk of suffering an injury was merely one of many risks which had to be assessed. Even though the facilitators guided discussion through a series of prompts, participants still discussed a wider range of issues than would be included perhaps by public health experts as "accident risks". These included being abducted by strangers, witnessing violent crime, and the threats of racist violence.

Formal injury prevention advice, of the sort that most of these participants could refer to knowledgeably, such as being careful of railway doors, or looking right and left when crossing the road, is only one factor contributing to children's knowledge of risk and safety. Knowledge is local, in that is constructed by particular peer group norms such as those discussed above. It is also local in that general information about risks is interpreted in the light of knowledge about the local physical environment and, more significantly, the social environment of peer group norms.

Health promotion messages that encourage avoiding risks were seen to be based largely on general prohibitions. These seem to be successful in terms of "knowledge": they were recited accurately by children in many of the groups we talked to. However, although the children in these groups were adept at the preventative "logic" upon which such advice was based, they were also sophisticated in their critique of the applicability of this, which was often seen to be less useful in practice than it appeared in theory. As providing specific advice about every danger that children will face is clearly impossible - as the children themselves point out, there are far too many "risk factors" to consider - an additional approach might be to build on the strengths and competencies in preventing injuries that children already possess. Their competence springs as much from experiential learning and a growing awareness of their own physical abilities as from formal health promotion advice.

The children we talked to had wide repertoires of risk avoidance strategies. Although we have no data on which of these were utilised in real situations, we have highlighted the ones children thought it important enough to discuss. The transcripts include many examples of children calling on knowledge that they have gained through experience: through learning to cross roads safely, through misjudging risks themselves, and through seeing the consequences of friends' and relatives' risk taking behaviour. Personal experience (of others who had been run over, or trapped in railway doors) was reported as a significant, and culturally legitimate, influence on behaviour. Injury prevention advice could build on this personal experience, or use characters from popular television serials identified as "peer equivalents". Such experience was more easily drawn on in these discussions as a legitimate way to defend risk reduction than the advice of professionals or other adults.

It is perhaps artificial to separate injury prevention from other risk management activities in which children engage. For these children, accident experiences were intricately bound up with other areas of life: establishing friendships, counteracting boredom, or testing developing skills. Education that focuses narrowly on injury risks is likely to be seen as irrelevant, or at least marginal, to children's everyday concerns.

A final minor point is that taped discussions, even though they were used here for research purposes, may have some educational use. The participants in all our groups wanted to hear their own discussions on tape at the end of the session, and commented on their own discussion when it was played back to them. Listening to a discussion, particularly one that was more "guided" than ours, could be used to reinforce safety messages if they were seen to have been contributed by the children themselves.

\section{Conclusions}

Focus group discussions were a useful way of accessing children's knowledge about injury risks, and how that knowledge was situated in the context of their social lives. The children we talked to were sophisticated in their understanding of the causes of injuries, and, like the experts, saw these misfortunes arising from complex webs of risk factors that could be managed, and, crucially, were their own responsibility to manage adequately. Their stories about suffering and preventing injuries suggested that educational interventions that draw on their own competencies and knowledge may be more effective than those that are generalised and do not refer to their own local environments. Educational projects based on a more integrated approach to risk management, rather than stressing "dangers" in isolation, are most likely to resonate with children's own perceptions.

Funding for this study was provided by the School of Education, Politics and Social Sciences at South Bank University, where ful to Professor Judith Allsop, for comments on the first draft; to ful to Profssor Judith Allsop, for comments on the first draft; to Tona Aitsilarbi, who set up, facilitated, and transcribed three of the focus groups; to the teachers, head teachers, and youth club leaders who arranged access; and particularly to all the children who participated in the discussions. 
1 Towner EML. Preventing childhood unintentional injuries-what works? A literature review. Inj Prev injuries-what

2 Speller V, Mulligan JA, Law C, et al. Preventing injury to children and young people. Southampton: Wessex Institute of Public Health, 1995.

3 Harker P, Moore L. Primary health care action to reduce home accidents: a review. Health Education fournal 1996;53:322-31

4 Towner EML. The role of health education in childhood injury prevention. Inj Prev 1995;1:3-8.

5 Wolley A. The risk pack: a teacher's resource to help children assess and manage risk. London: Child Accident Prevention Trust, 1996.

6 Roberts H, Smith S, Lloyd M. Safety as social value: a community approach. In: Scott S, Williams G, Platt S, et al, eds. Private risks and public dangers. Aldershot: Avebury, 1992.

7 Mayall B. Children, health and the social order. Buckingham: Open University Press, 1996.
8 James A. Childhood identities: social relationships and the self in children's experiences Edinburgh: Edinburgh University Press, 1993.

9 Alderson P. Children's consent to surgery. Buckingham: Open University Press, 1993

10 Haudrup Christensen P. The social construction of help among Danish children: the intentional act and the actual content. Sociology of Health and Illness 1993;15:488-502.

11 Kitzinger J. The methodology of focus groups. Sociology of Health and Illness 1994;16:103-21.

12 Mayall B. Keeping healthy at home and school. Sociology of Health and Illness 1993;15:464-87.

13 Strauss A. Qualitative analysis for social scientists. Cambridge: Cambridge University Press, 1987.

14 Green J, Hart L. The impact of context on data. In: Barbour , Kitzinger I, eds. Developing focus group research. London: Sage (in press).

15 Department of Health. The health of the nation key area handbook: accidents. Leeds: Department of Health, 1993.

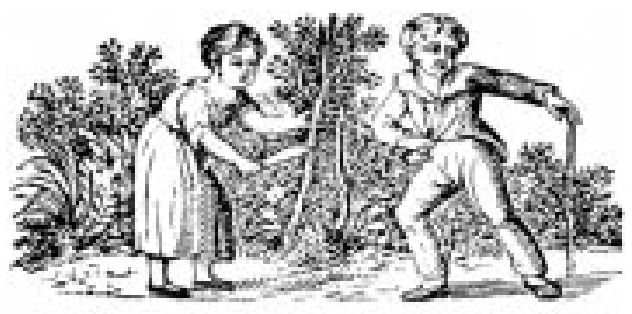

PI.AYING WITH KNIVES.

Nothing is so foolish and danzerous as to play with knives, scissors, and forks. Mad wounds are oftent the conseguence, and many childeen have thus lost their lixes, Here is a little boy wha has had his hasd haif cut off by the carelessness of lis little sister. They went fusth into the fields with rery sharp knixes, to sather flowers and to cut boughs for the purpase of decorating their rooms. As they wre cutting slown a very large une, the little girl's kuife slippesl, struck hee bruther's hasd, and usade an incisiun to the bune; the bloud flexed copiously, the boy cried heartily, and all this lappened for want of proper care on the part of the little girl. Children sometimes procure very sharp knives, which they earry shost with them in their pockets, and to test the sharpness of them, they are often cutting elasirs, Jesks, and tables, and whittling about the liousc, mmeh against their parent's wishes, to their own danger, and to the anaoy. ance of the huse-maind.

From The Book of Accidents; Designed for Young Children, New Haven, 1830. 